\title{
RP-HPLC method development and validation for the quantification of Efonidipine hydrochloride in $\mathrm{HME}$ processed solid dispersions
}

\author{
Ashish S. Rajput, Durgesh K. Jha, Sharda Gurram, Devanshi S. Shah and Purnima D. Amin ${ }^{*}$
}

\begin{abstract}
Background: Efonidipine hydrochloride (EFO) is a poorly water-soluble drug and, hence, has poor bioavailability. Solid dispersions (SDs) of EFO using Eudragit EPO were prepared using hot-melt extrusion (HME) for the first time. The current study aims at developing a simple RP-HPLC method to quantify EFO in the developed SDs.

Results: The chromatographic separation was carried out on an Agilent Eclipsed XDB-C18 column (4.6 × $250 \mathrm{~mm}$ ), packed with $5 \mu \mathrm{m}$ particles. The optimized mobile phase consisted of HPLC grade acetonitrile and $0.020 \mathrm{~mol} / \mathrm{L}$ $\mathrm{KH}_{2} \mathrm{PO}_{4}(\mathrm{pH} 2.5)$ buffer in the ratio of $85: 15 \mathrm{~V} / \mathrm{V}$ with a flow rate optimized at $1.2 \mathrm{ml} / \mathrm{min}$. The developed method was validated for system suitability, linearity, accuracy, precision, and robustness. The linearity results showed an excellent linear relationship between the drug concentration and peak area, indicating the peak area is directly proportional to the analyte concentration within a specific range and an excellent correlation coefficient of 0.9998. Intermediate precision and repeatability confirmed that the method provides precise results with \%RSD value less than $2 \%$ for EFO. The assay results of the developed formulations were in the acceptable range with RSD less than $2 \%$. The enhanced drug dissolution from the Eudragit EPO carrier with 10\% Citric Acid (CA) is attributed to the conversion of the drug from crystalline to amorphous form, and microenvironmental acidic pH provided by CA.

Conclusion: In a nutshell, the developed RP-HPLC method showed excellent ability to differentiate the formulations and highlights the role of the polymer and the plasticizer.
\end{abstract}

Keywords: Efonidipine hydrochloride, Hot-melt extrusion, RP-HPLC, Micro-environmental pH, Solid dispersion

\section{Background}

Efonidipine hydrochloride (EFO) (Fig. 1) is a novel 1,4dihydropyridine derivative calcium channel antagonist. Chemically, it is 2-(phenyl-(phenylmethyl) amino) ethyl

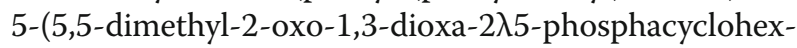
2-yl)-2,6-dimethyl-4-(3-nitrophenyl)-1,4-dihydropyridine-3 carboxylate with empirical formula of $\mathrm{C}_{34} \mathrm{H}_{38} \mathrm{~N}_{3} \mathrm{O}_{7} \mathrm{P}$ and molecular weight of 631.65 . It is a pale yellowish powder with a melting range of 154.7 to $172.0^{\circ} \mathrm{C}$ and a very high boiling point of $746.9^{\circ} \mathrm{C}$. The

\footnotetext{
* Correspondence: purnima.amin@yahoo.co.in

Department of Pharmaceutical Sciences and Technology, Institute of Chemical Technology, Matunga 400019, India
}

drug has a $\log P$ value of 5.44, which confirms its lipophilic nature. EFO is insoluble in water $(<10 \mu \mathrm{g} / \mathrm{ml})$ but soluble in DMSO $(5 \mathrm{mg} / \mathrm{ml})$, methanol, ethanol, and acetonitrile [1]. The poor aqueous solubility of the drug poses a challenge for the drug bioabsorption and hence bioavailability.

A simple yet very promising approach to enhance the solubility of the drug is the preparation of amorphous solid dispersions. Various techniques for preparing solid dispersions (SDs) of EFO for solubility enhancement, such as spray drying [2], freeze-drying [2], microwave treatment [3], and nanosuspension using a ball mill [4], have been worked upon by several researchers. In the 
<smiles>CC1=C(C(=O)OCCN(Cc2ccccc2)c2ccccc2)C(c2cccc([N+](=O)[O-])c2)C(P2(=O)OCC(C)(C)CO2)=C(C)N1</smiles>

Molecular weight: $668.1 \mathrm{~g} / \mathrm{mol}$

Fig. 1 Efonidipine hydrochloride

current research, the solid dispersion of EFO was prepared, using the hot-melt extrusion technique (HME), for the first time. HME is a process wherein high shear mixing of the molten mass comprising of drug and polymer brings intermolecular interactions between them, causing the drug to disperse in the carrier at a molecular level. The basic thermoplastic polymer that is investigated for SD using HME is Eudragit EPO. Generally, to ease the processing of the drug-polymer mixtures and to reduce the processing temperature, various solid or liquid plasticizers are employed that include citric acid (CA), poloxamer 407, propylene glycol, and glycerol [5]. The current study employs CA as a solid-state plasticizer for the HME processing of the polymer at lower concentrations, reducing the processing temperature substantially. This behavior of $\mathrm{CA}$ is attributed to the high capacity of hydrogen bond formation with the polymer, confirmed by several reports [5-7]. Also, CA is a microenvironmental $\mathrm{pH}$ acidifier that helps to provide the desired drug release rate in any environmental $\mathrm{pH}[8,9]$. Herein, we propose to develop SD using a thermoplastic polymer, Eudragit EPO, and a solid-state plasticizer, CA.

The developed formulations necessitate the use of an appropriately validated method to quantify the drug and study the drug release. EFO is not official in any of the pharmacopeias, and hence, there is no pharmacopeial method of analysis for the quantification of the drug in bulk and pharmaceutical formulations. A detailed literature search gives information on several methods developed for EFO analysis, i.e., LC-MS/MS for estimation of the drug in plasma [10], LC-MS/MS for stereospecific estimation of the drug in plasma [11], RP-HPLC method for estimation of the drug from tablet dosage forms [12], and RP-HPLC method for forced degradation study of EFO [13]. So far, none of the reports shows a method of analysis for the estimation of EFO content and the drug release from the SD formulations. In the current method, we propose to develop and validate a simple, reliable, and accurate RP-HPLC method for the quantification of EFO and determine the drug release from the developed SDs.

\section{Methods}

Chemicals and reagents

Efonidipine hydrochloride was provided as a gift sample by Bajaj Healthcare Ltd. Eudragit EPO was gifted by Evonik Industries (India). HPLC grade acetonitrile was purchased from Merck, Germany, and orthoboric acid was purchased from Avantor pharma, Mumbai. Before use, phosphate buffer solution ( $\mathrm{pH} 2.5)$ was prepared using deionized water (Milli- ${ }^{\circ}$, Moslheim, France). Other chemicals like analytical grade citric acid were purchased from SD Fine Chemicals Ltd.

\section{Preparation of solid dispersions}

Solid dispersions of EFO were prepared using $30 \%$ of the drug, 60\% Eudragit EPO, 10\% CA (SD1), and the other without CA (SD2). The premixed drug and polymeric carrier were sifted through \#60 and blended with a weighed amount of plasticizer. The prepared mixtures were processed at a temperature of $120 \pm 2{ }^{\circ} \mathrm{C}$ and speed of $100 \mathrm{rpm}$ on a twin screw hot-melt extruder (Thermo Scientific HAAKE MiniCTW, Germany). The extrudes of $0.5 \mathrm{~mm}$ diameter die were collected, dried, powdered, and subjected for further studies.

\section{Method development \\ Instrumentation}

The chromatographic separation was accomplished on a Jasco AS-2055 plus series intelligent sampler (Jasco, Tokyo, Japan) equipped with an automatic sample injector, Jasco MD-2018 $8_{\text {Plus }}$ Intelligent HPLC pump, photodiode array (PDA Detector), rheodyne injection valve, online degasser, and Agilent Eclipsed XDB-C18 column $(4.6 \times 250 \mathrm{~mm})$ packed with $5 \mu \mathrm{m}$ particles. Milli-Q water was obtained by the Millipore system (Moslheim, France). Sonicator was from Enertech fast ultrasonicate cleaner, Mumbai, and vacuum pump model no TID-15 of Conformite Europeenne with a vacuum of $22 \mathrm{mmHg}$.

\section{Chromatographic conditions}

The optimized composition of the mobile phase was set in the ratio 85:15 (v/v) of HPLC grade acetonitrile and phosphate buffer ( $\mathrm{pH} 2.5$ ), respectively, under the gradient method of the elution process. The flow rate of the mobile phase was $1.2 \mathrm{ml} / \mathrm{min}$ with an injection volume of $50 \mu \mathrm{l}$, and the detection wavelength was kept at 252.0 $\mathrm{nm}$ as the $\lambda_{\max }$. The column equilibration was carried out for $15 \mathrm{~min}$ before the start of the analysis. All experiments were conducted at a temperature of $25 \pm 2{ }^{\circ} \mathrm{C}$. 
The total peak area of the drug was used to estimate the concentration of EFO. Chromatograms were recorded using ChromNAV software. These conditions were inspected to achieve an easy to use, cost-effective, and reliable procedure with a better peak resolution for symmetry, tailing factor, and early retention time.

\section{Preparation of stock solution and standard solutions}

One hundred micrograms/milliliter of the stock solution was prepared by dissolving $10 \mathrm{mg}$ of EFO in $50 \mathrm{ml}$ of HPLC grade acetonitrile in a 100-ml volumetric flask. This drug solution was sonicated for $15 \mathrm{~min}$ to solubilize the remaining drug particles. The final volume of the solution was made up of HPLC grade acetonitrile. The working standard solutions were prepared by diluting the stock solution of concentration $100 \mu \mathrm{g} / \mathrm{ml}$ using HPLC grade acetonitrile in the range of $2.5-100 \mu \mathrm{g} / \mathrm{ml}$.

\section{Method validation}

The developed chromatographic method was validated according to the International Council for Harmonization (ICH) guidelines Q2 (R1) [14].

\section{System suitability}

System suitability test is performed to demonstrate the suitability of the system for the analysis. The fresh standard stock solution of EFO was prepared to check for the suitability of the method. The sample solution of concentration $100 \mu \mathrm{g} / \mathrm{ml}$ was injected six times at regular short time intervals. The peak area, retention time, resolution, theoretical plate, and tailing factor were recorded as the system suitability parameters using the software under optimized chromatographic conditions to examine the suitability of the system. The results were analyzed by determining the standard deviation of all the parameters of the system suitability study. The acceptance criteria and the limits for RSD were in concordance to USP limits [15-17].

\section{Linearity and range}

The method was validated for linearity by injecting the sample solutions of concentration 2.5, 5, 10, 25, 50, and $100 \mu \mathrm{g} / \mathrm{ml}$ for analysis. Each sample solution was injected three times. The peak area of each solution was recorded at $\lambda_{\max }$ of $252.0 \mathrm{~nm}$. The peak area corresponding to each concentration was determined from the recorded chromatograms. The graph of peak area on the $y$-axis versus concentration on the $x$-axis was plotted. The results were recorded for the regression coefficient $\left(R^{2}\right)$, the slope of the regression line, and the $y$-intercept. The $R^{2}>0.999$ was set as the acceptance criteria for the linearity of the developed method [16].

\section{Method precision}

The intermediate precision (inter-day precision) and repeatability (intra-day precision) of sample solutions were examined to check whether the developed method shows precise results on repeated samplings at any point in time. Standard solutions of EFO of concentrations $2.5,5,10,25,50$, and $100 \mu \mathrm{g} / \mathrm{ml}$ were prepared and injected into the HPLC system. The intra-day precision study was carried by injecting each concentration of the sample solutions of EFO in triplicates on the same day. The inter-day precision study was carried by injecting each concentration of the sample solutions of EFO on three consecutive days over 2 weeks. The peak area of all six solutions, detected at a $\lambda_{\max }$ of $252.0 \mathrm{~nm}$, and $\%$ relative standard deviation (RSD) was calculated from the recorded chromatograms. The acceptance criteria for the $\%$ RSD was kept as $\leq 2 \%[16,18]$.

\section{Robustness}

Robustness is the measure of sustainability, i.e., to remain unaffected by deliberate variations in the essential parameters of the chromatographic conditions and also provide knowledge on the implications of its variations. In the current robustness study, the two parameters mobile phase ratio and flow rate were considered for minute deliberate changes in the method, to check whether the changes majorly affect the peak areas and the retention time. The selected two parameters were studied at three different levels, i.e., $85 \pm 2: 15 \pm 2 \mathrm{v} / \mathrm{v}$ and $1.2 \pm 0.2$ $\mathrm{ml} / \mathrm{min}$ for mobile phase ratio and flow rate, respectively, to verify the robustness of the proposed HPLC method. The constant standard solutions of $10 \mu \mathrm{g} / \mathrm{ml}$ were prepared and injected for the evaluation of the parameters. The standard deviation of the peak areas and the retention time were calculated from the recorded chromatograms.

\section{Accuracy (percentage recovery)}

Accuracy is defined as the closeness of the test value of the method in comparison with the expected value. It is calculated in terms of percentage recovery of the analyte using the following equation [16].

$$
\text { Percentage recovery }=\frac{\text { Recovered concentration }}{\text { Injected concentration }} \times 100
$$

The percentage recovery of the EFO was determined by spiking a known amount of the drug into the sample solution. The known concentration solutions of $20 \mu \mathrm{g} /$ $\mathrm{ml}$ and $45 \mu \mathrm{g} / \mathrm{ml}$ were added to the sample solution of $5 \mu \mathrm{g} / \mathrm{ml}$ to obtain the final concentrations of $25 \mu \mathrm{g} / \mathrm{ml}$ and $50 \mu \mathrm{g} / \mathrm{ml}$. The amount of EFO was estimated by measuring the peak area from the recorded chromatograms. Each sample concentration was injected in 
triplicate to estimate the percentage recovery of the EFO in the spiked samples. The acceptance criteria for the percentage recovery is $98-102 \%$.

\section{Limits of detection (LOD) and limits of quantitation (LOQ)}

The lowest concentration of an analyte, which can be identified specifically from the background noise levels, is known as the limit of detection (LOD). The minimum amount of the analyte, which can be quantified effectively with precision and accuracy using the developed method, is known as the limit of quantification (LOQ). LOD and LOQ were determined from the standard deviation of the intercept and the slope of the calibration curve. The following equation as per ICH guidelines was then applied to determine the values:

$$
\mathrm{LOD}=3.3 \times \sigma / \mathrm{S} ; \mathrm{LOQ}=10 \times \sigma / S
$$

where $\sigma$ is the standard deviation of $y$-intercepts of regression lines and $S$ is the slope of the calibration curve [18].

\section{Specificity}

Accurate determination of the drug in the presence of other excipients without any interference is termed as specificity. The excipient interferences in SD formulations were evaluated during the analysis, and the results were compared with the placebo batches to determine the specificity of the developed method for EFO.

\section{Assay}

The prepared SD of EFO was examined for the drug content using the developed and validated HPLC method. The formulation equivalent to $10 \mathrm{mg}$ of EFO was weighed accurately in the volumetric flask. A solution equivalent to $10 \mu \mathrm{g} / \mathrm{ml}$ concentration was prepared and quantified using the developed HPLC method. The experiments were performed in triplicate.

\section{Stability of the analyte solution}

The drug in the stock solution was evaluated by preparing $100 \mu \mathrm{g} / \mathrm{ml}$ solutions in acetonitrile. The test solutions were kept in tightly sealed vials at room temperature for $24 \mathrm{~h}$. The solutions were analyzed by using the developed HPLC method for drug stability. The measured values were computed to determine the \%RSD values.

\section{Characterization of the SD In vitro dissolution study}

The dissolution experiments were performed in the 6.8 $\mathrm{pH}$ phosphate buffer at a temperature of $37^{\circ} \mathrm{C}$ and the paddle speed of $75 \mathrm{rpm}$ in USP apparatus II. The dissolution experiment was conducted on the developed SDs and EFO. The SDs equivalent to $20 \mathrm{mg}$ drug and the pure drug were weighed accurately and added to each vessel. The dissolution behavior of each sample was investigated in triplicates. Samples withdrawn at predetermined intervals were filtered through a $0.45-\mu \mathrm{m}$ Whatman filter. The amount of drug dissolved from the pure form of the drug and the SD was determined using the developed HPLC method.

\section{Powder X-ray diffractometry (PXRD)}

Powder X-ray diffraction patterns for EFO and the selected SD was studied using X-ray diffractometer (XRD) Shimadzu XRD 6100 (Japan). Cu-Ka X-ray source was used with $\lambda=1.54^{\circ} \mathrm{A}$, and the scanning rate was monitored at $2 \% \mathrm{~min}$. The samples were measured with a voltage of $40 \mathrm{kV}$ and a current of $20 \mathrm{~mA}$. Each sample was scanned over a diffraction range of $2^{\circ}$ to $60^{\circ}$.

\section{Differential scanning calorimetry (DSC)}

The thermal analysis and the drug-polymer interactions of the pure EFO and selected SD formulation, respectively, were carried out using DSC-PYRIS-1, Perkin Elmer, USA. The experiments were performed in a dry nitrogen atmosphere. The accurately weighed 5-mg samples were heated at the rate of $10^{\circ} \mathrm{C} / \mathrm{min}$ under nitrogen purge $(20 \mathrm{ml} / \mathrm{min})$ from 30 to $300^{\circ} \mathrm{C} / \mathrm{min}$. An empty crimped aluminum pan was used as a reference cell.

\section{Results}

\section{Method development}

Table 1 summarizes the optimized chromatographic conditions of the developed RP-HPLC method.

\section{Method validation \\ System suitability}

A typical chromatogram of EFO is represented in Fig. 2. Results of the $100 \mu \mathrm{g} / \mathrm{ml}$ concentration solution in six replicate runs showed that the developed method was suitable for pharmaceutical analysis. Table 2 shows the system suitability parameters for the recorded peak areas. The \%RSD results were found to be below $1 \%$ for all the parameters. The column efficiency was found to be 3047.68 theoretical plates with a tailing factor of 1.257.

\section{Linearity}

The linear calibration curve was obtained for EFO by plotting the concentration on the $x$-axis and mean peak area for six replicate analyses of each concentration on the $y$-axis. The graph showed a good linear relationship between the EFO concentration and the peak area in the concentration range of $2.5-100 \mu \mathrm{g} / \mathrm{ml}$, with the regression coefficient of 0.9997 . The regression line equation was $y=2049.3 x-79$. Figure 3 depicts the results of the linearity. 


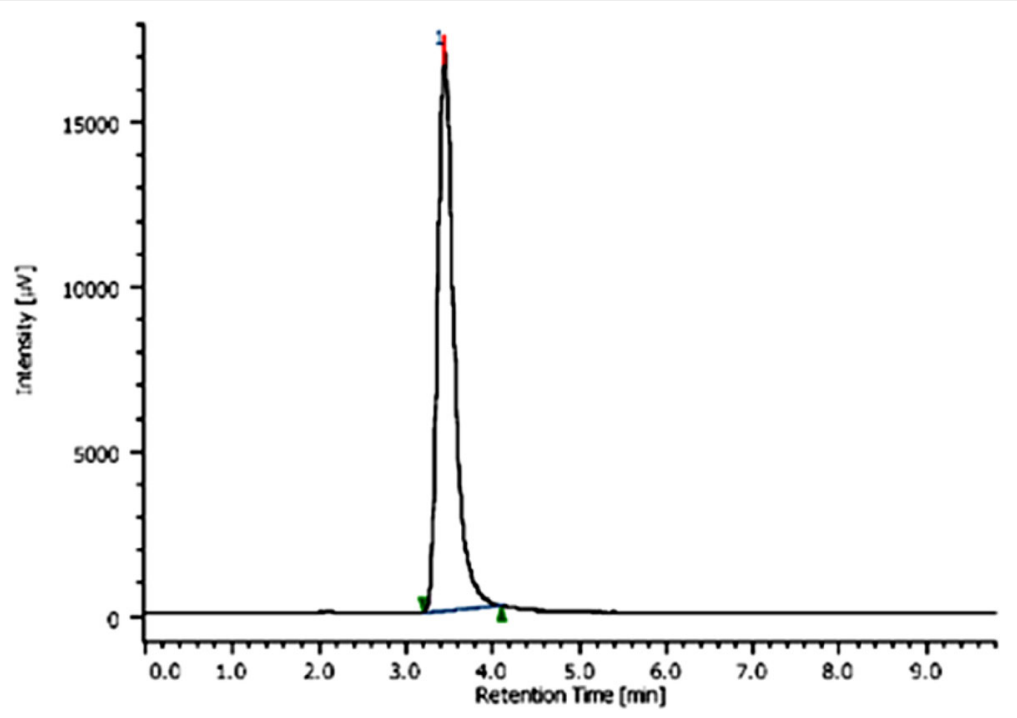

Fig. 2 Standard chromatogram of Efonidipine hydrochloride

\section{Precision}

The results of the intra-day and inter-day variations of the method shows that the method is very precise and repetitive. The \%RSD results of the inter-day and intraday precision were below $1 \%$, complying with the acceptance criteria limit of $2 \%$. Table 3 summarizes the results of intra-day and inter-day precision.

\section{Robustness}

The developed HPLC analytical method was studied for its robustness by intentionally modifying the mobile phase composition and the flow rate, as mentioned earlier. The results of the robustness are presented in terms of \%RSD for the runs conducted at specified conditions. The results (Table 4) showed that the \%RSD for the deliberate variation made in the mobile phase and the flow rate are below 2. It is evident from these results that the method is not impacted with the small variations in the mobile phase compositions and the flow rate. This ensures that the method is robust producing accurate and precise results inspite of small changes in the chromatographic conditions as the values obtained fall within the acceptable limits.

\section{Accuracy}

The accuracy results obtained by the developed analytical method is expressed in terms of percent recovery. The results of the percent recovery for the concentrations evaluated were within limits specified earlier, i.e., $98 \pm 102 \%$. The results of the percentage recovery showed that the method is appropriate for its use in routine analysis. Table 5 depicts the results of accuracy.

\section{Limit of detection (LOD) and limit of quantification (LOQ)}

The LOD and LOQ values are evaluated, as mentioned earlier. The relative standard deviation of the intercept and slope of the regression line from the linearity graph was used to determine the LOD and LOQ values. The LOD and LOQ of EFO were found to be $0.34 \mu \mathrm{g} / \mathrm{ml}$ and $1.04 \mu \mathrm{g} / \mathrm{ml}$, respectively. These values indicate that the

Table 1 Optimized chromatographic condition

\begin{tabular}{ll}
\hline HPLC unit & Jasco AS-2055 plus series intelligent sampler \\
\hline Stationary phase (column) & Agilent Eclipsed XDB-C18, $(4.6 \times 250$ mm) packed with $5 \mu$ m particles \\
Detector & Photodiode detector (PDA) \\
Mobile phase & ACN, phosphate buffer $2.5 \mathrm{pH}(85: 15)$ \\
Detection wavelength $(\mathrm{nm})$ & 252.0 \\
Run time $(\mathrm{min})$ & 6 \\
Flow rate $(\mathrm{ml} / \mathrm{min})$ & 1.2 \\
Volume of injection loop $(\mu \mathrm{L})$ & 50 \\
Column temperature & Ambient \\
\hline
\end{tabular}


Table 2 System suitability parameters

\begin{tabular}{ll}
\hline Parameters & Values \\
\hline Retention time (mins) & $3.4 \pm 0.1$ \\
Theoretical Plates & $3047.68 \pm 2 \%$ \\
Tailing factor & $1.257 \pm 0.1$ \\
Linearity range $(\mu \mathrm{g} / \mathrm{ml})$ & $2.5-100$ \\
Limit of detection $(\mathrm{LOD})(\mu \mathrm{g} / \mathrm{ml})$ & 0.34 \\
Limit of quantitation $(\mathrm{LOQ})(\mu \mathrm{g} / \mathrm{ml})$ & 1.04 \\
Relative standard deviation $(\% \mathrm{RSD})$ & $<1 \%$ \\
\hline
\end{tabular}

developed method is highly sensitive. Table 2 depicts the LOD and LOQ values.

\section{Specificity}

The chromatograms of the EFO in developed SDs and the placebo SDs showed no interference of the excipients with the peak of EFO. Hence, the method is considered specific for the determination of EFO in the developed formulations.

\section{Assay}

The content of the drug in the SDs was determined using the validated RP-HPLC method. Assay results show EFO content in both the SDs to remain in the range of $99.1-100.8 \% \mathrm{w} / \mathrm{w}$, as shown in Table 6 . The results obtained are within the limits of percentage-labeled claim required, with \%RSDs less than $2 \%$.

\section{Solution stability}

The sample solutions showed excellent stability when analyzed by the developed RP-HPLC method at an initial and $24 \mathrm{~h}$ time point. This observation shows that the drug solution remains stable in the diluting solvent acetonitrile for a period of $24 \mathrm{~h}$. The calculated \%RSD of

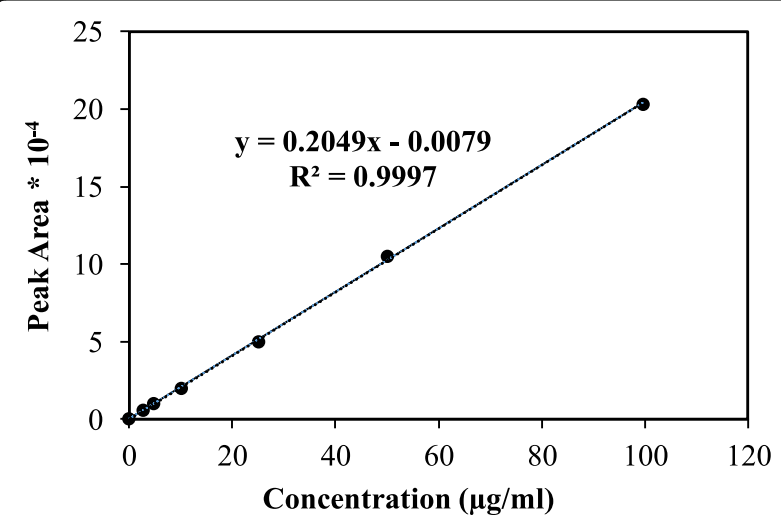

Fig. 3 Linearity graph
Table 3 Precision data at different concentration levels

\begin{tabular}{lllll}
\hline $\begin{array}{l}\text { Concentration } \\
\text { of EFO }\end{array}$ & \multicolumn{4}{l}{ Observed concentration $(\boldsymbol{n}=\mathbf{6})$} \\
\cline { 2 - 5 } & Interday & \%RSD & Intraday & \%RSD \\
\hline 2.5 & 4545.5 & 0.202 & 4617 & 0.015 \\
5 & 9626.5 & 0.507 & 9243 & 0.673 \\
10 & 19319.5 & 0.890 & 19471.5 & 0.535 \\
25 & 48918.0 & 0.809 & 50741 & 0.059 \\
50 & 106026.5 & 0.422 & 103738.5 & 0.507 \\
100 & 203719.5 & 0.423 & 201683.5 & 0.210 \\
\hline$n=$ mean of six value & & & &
\end{tabular}

area and retention time were found to be 0.758 and 0.825 , respectively.

\section{Characterization of the SD In vitro drug release}

The drug release from its SD formulation was determined using the validated HPLC method. From Fig. 4, it is evident that the percentage of drug release at the end of $60 \mathrm{~min}\left(\mathrm{Q}_{60}\right)$ from the SD formulation with (SD1) and without CA (SD2) as a plasticizer is $87 \%$ and $39 \%$, respectively. These values are 51 times and 23 times higher than that of pure EFO, respectively, which was found to be $1.7 \%$.

\section{Powder X-ray diffractometry (PXRD)}

Sharp and intense crystalline peaks at $2 \theta$ values of $5.6^{\circ}$, $7.4^{\circ}, 10.6^{\circ}, 12.4^{\circ}, 13.0^{\circ}, 13.9^{\circ}, 18.06^{\circ}, 20.4^{\circ}, 23.14^{\circ}, 24.14^{\circ}$, and $26.5^{\circ}$ were observed in the diffraction spectrum of pure EFO and broadened peaks with a halo pattern were observed for the extrudates (SD1) as shown in Fig. 5.

\section{Differential scanning calorimetry (DSC)}

From the DSC curve shown in Fig. 6 an endothermic peak of pure EFO at $172.02{ }^{\circ} \mathrm{C}$ is observed which corresponds to the melting point of EFO. On the other hand, the DSC thermogram of SD1 demonstrates the disappearance of the melting endotherm.

\section{Discussion}

\section{Method development and validation}

EFO, having the $\log P$ of 5.44 and $\mathrm{pK}_{\mathrm{a}}$ of 3.5 (strongest basic) and 19.49 (strongest acidic) [3], is insoluble in water and shall remain ionized at $\mathrm{pH}$ around 2-4 due to the presence of proton accepting group ( $\mathrm{pKa} 3.5$ ) in the molecule. The theory of HPLC states that the ionized molecules have a lesser affinity with the C18 column and hence, aids in faster elution of the molecule from the column and thus provides reduced retention time [19]. Due to this reason, the preliminary experiments were carried out using a mixture of organic solvent (acetonitrile or methanol) and phosphate buffer ( $\mathrm{pH} 2-$ 
Table 4 Robustness parameters

\begin{tabular}{|c|c|c|c|c|c|c|}
\hline \multirow[t]{2}{*}{ Parameter } & \multicolumn{2}{|c|}{ Method condition } & \multirow{2}{*}{$\begin{array}{l}\text { Mean peak } \\
\text { Area } \pm \text { SD }\end{array}$} & \multirow[t]{2}{*}{$\%$ RSD } & \multirow[t]{2}{*}{$\mathrm{Rt} \pm \mathrm{SD}$} & \multirow[t]{2}{*}{$\%$ RSD } \\
\hline & Original & Variation & & & & \\
\hline \multirow{3}{*}{$\begin{array}{l}\text { Flow rate } \\
(\mathrm{ml} / \mathrm{min})\end{array}$} & \multirow[t]{3}{*}{1.2} & 1.4 & \multirow{3}{*}{$\begin{array}{l}19,425.2 \pm \\
91.61\end{array}$} & \multirow[t]{3}{*}{0.472} & \multirow{3}{*}{$\begin{array}{l}3.45 \pm \\
0.036\end{array}$} & \multirow[t]{3}{*}{1.04} \\
\hline & & 1.2 & & & & \\
\hline & & 1.0 & & & & \\
\hline \multirow{3}{*}{$\begin{array}{l}\text { Mobile phase } \\
\text { (ACN to pH } 2.5 \\
\text { phosphate } \\
\text { buffer) }\end{array}$} & \multirow[t]{3}{*}{$85: 15$} & $87: 13$ & \multirow{3}{*}{$\begin{array}{l}19,352.7 \pm \\
79.95\end{array}$} & \multirow[t]{3}{*}{0.41} & \multirow{3}{*}{$\begin{array}{l}3.43 \pm \\
0.04\end{array}$} & \multirow[t]{3}{*}{1.16} \\
\hline & & $85: 15$ & & & & \\
\hline & & $83: 17$ & & & & \\
\hline
\end{tabular}

Concentration: $10 \mu \mathrm{g} / \mathrm{ml}$

4) as the mobile phase composition at different volume ratios until a well resolved sharp peak symmetry and considerable retention time was obtained during the analysis. Finally, the optimized mobile phase composition consisted of the acetonitrile and phosphate buffer of $\mathrm{pH} 2.5$. Of the two organic solvents accounted for study, acetonitrile acted as an organic modifier showing better elution and peak symmetry in comparison with methanol [20]. The optimized chromatographic conditions for the stated column are a composition ratio of $85: 15 \mathrm{v} / \mathrm{v}$ acetonitrile-phosphate buffer $\mathrm{pH} 2.5$ with a flow rate of $1.2 \mathrm{ml} / \mathrm{min}$, injection volume $50 \mu \mathrm{l}$, run time $6 \mathrm{~min}$, and column temperature being ambient conditions. These chromatographic conditions produced the best-resolved peak symmetry with an active retention time of approximately $3.44 \mathrm{~min}$ and reduced tailing factor. EFO reference standard solution was scanned using the photodiode array detector, which showed absorbance maxima $\lambda_{\max }$ of $252.0 \mathrm{~nm}$. The developed method with reduced retention time prevents drug degradation during analysis. Additionally, multiple samples can be evaluated in a shorter period. The developed method was found to be a simple, accurate, robust, and reliable method with a significantly shorter retention time of $3.44 \pm 0.1 \mathrm{~min}$, and the tailing factor is 1.2 , which shows that the peak obtained is well acceptable.

\section{Characterization of SD}

The initial solubility of EFO could be attributed to the hydrochloride salt form, which gives an acidic environment but fails to maintain the dissolved state of the drug due to non-sink conditions. Such behavior leads to

Table 5 Accuracy data

\begin{tabular}{llllll}
\hline EFO concentration & $\begin{array}{l}\text { Amount } \\
\text { Added } \\
\text { (mg) }\end{array}$ & $\begin{array}{l}\text { Theoretical } \\
\text { amount } \\
\text { present } \\
\text { (mg) }\end{array}$ & $\begin{array}{l}\text { Observed } \\
\text { mean } \\
\text { amount } \\
\text { (mg) }\end{array}$ & $\begin{array}{l}\text { \% mean } \\
\text { recovery }\end{array}$ & \%RSD \\
\hline 20 & 5 & 25 & $24.84 \pm 0.2$ & $99.36 \pm 0.5$ & 0.25 \\
45 & 5 & 50 & $49.605 \pm 0.2$ & $99.21 \pm 0.4$ & 0.15 \\
\hline
\end{tabular}

Table 6 Assay data

\begin{tabular}{lll}
\hline Formulation code & Mean assay content & \%RSD \\
\hline EFO & 99.74 & 0.11 \\
SD1 & 99.77 & 0.72 \\
SD2 & 99.78 & 0.53 \\
\hline
\end{tabular}

precipitation and hence downfall in total percentage release of drug at the end of $60 \mathrm{~min}$. Both the SDs, i.e., SD1 and SD2, give higher drug release from the formulation as compared to that of the pure EFO, possibly due to the conversion of crystalline EFO to its amorphous form. The amorphous form is the highest energy form of a pure compound which leads to faster dissolution rates. Comparing the two SDs, CA present in SD1 furnishes an acidic microenvironmental $\mathrm{pH}$ in the dissolution vessel, resulting in a higher drug release as compared to SD2. The XRD and DSC data confirm the conversion of the crystalline nature of EFO to an amorphous state. The disappearance of the drug peaks followed by a display of a halo pattern in the XRD diffractogram of SD1 confirms that the drug is amorphously dispersed in the polymeric matrix. The halo pattern of the diffraction spectrum is indicative of the transformation of crystalline form into an amorphous form [3] (Fig. 5).

Additionally, the DSC thermograms in Fig. 6 show a double hump with one characteristic melting endotherm peak shown at $172.02^{\circ} \mathrm{C}$, which is analogous, with that reported by Huang et al. [4]. In the same figure, the DSC thermogram of SD1 shows the absence of an endothermic peak at that temperature. The absence of the peak is an indication of the complete conversion of crystalline to amorphous form [3]. The amorphous form of the drug molecularly interacts with the polymer conferring the miscibility between the two, yielding solid

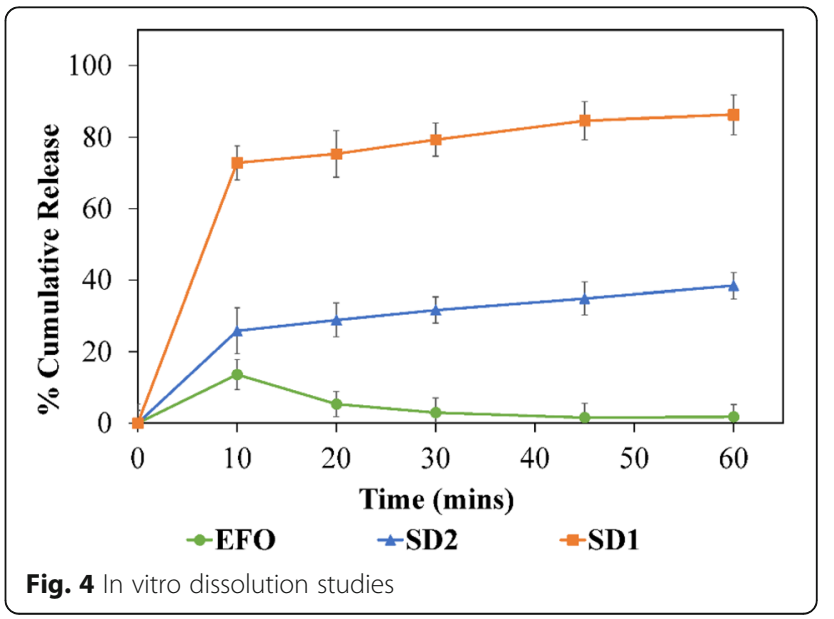




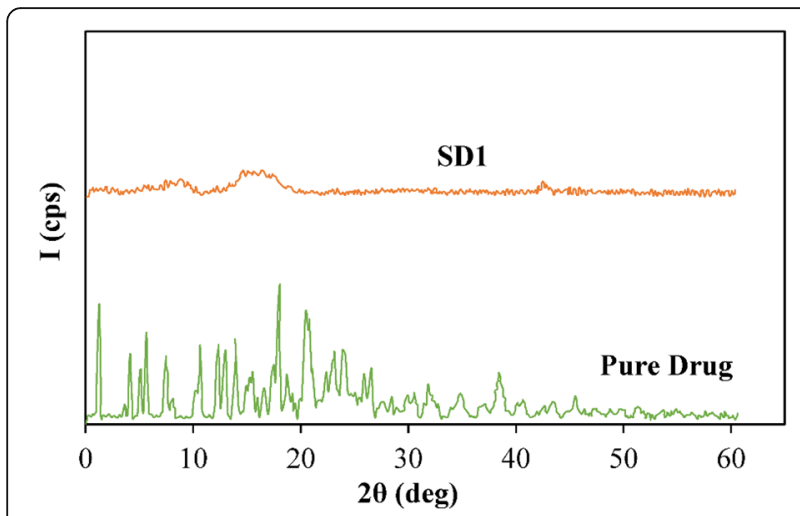

Fig. 5 X-ray diffractogram of pure drug and SD1 formulation

dispersion. DSC has been widely used to study such interactions [21].

\section{Conclusion}

The solubility and dissolution rate of poorly soluble EFO was enhanced by the solid dispersion approach using HME. CA in the formulation provides microenvironmental acidic $\mathrm{pH}$. Additionally, $\mathrm{CA}$ acts as a plasticizer for the easy processing of the HME. The successful SD preparation and EFO amorphization were confirmed using XRD and DSC. A new HPLC method was developed, optimized, and validated for the quantification of EFO from the SDs. The developed RP-HPLC method can successfully be adopted for the quantitative evaluation of EFO in assay, purity, stability, solubility study, and in vitro dissolution study. Overall, the method was found to be linear, accurate, precise, specific, sensitive, and robust with less time consumption. The method can be used for routine quality control of EFO in drug testing laboratories and pharmaceutical industries.

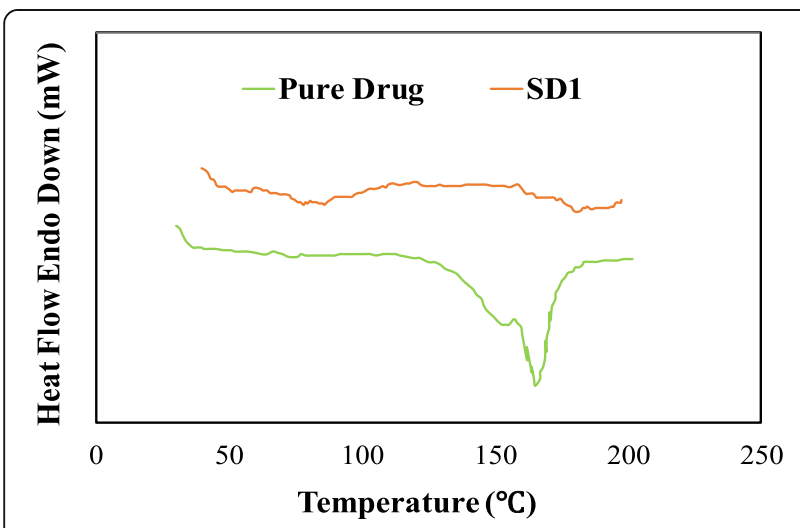

Fig. 6 DSC thermogram of pure drug and SD1 formulation

\section{Abbreviations}

EFO: Efonidipine hydrochloride; RP-HPLC: Reverse-phase high-performance liquid chromatography; ICH: International Conference on Harmonization; LOD: Limit of detection; LOQ: Limit of quantification; RSD: Relative standard deviation; DSC: Differential scanning calorimetry; XRD: X-ray diffraction; HME: Hot-melt extrusion; SD: Solid dispersion; CA: Citric acid

\section{Acknowledgements}

The authors are thankful to AICTE, India, for providing research fellowship.

\section{Authors' contributions}

All the authors have contributed to the study design. AR and DJ have performed the HPLC method development and validation study under the guidance of PA. AR, DJ, SG, and DS have drafted the manuscript as per the journal submission format. All authors read and approved the final manuscript.

\section{Funding}

Not applicable

Availability of data and materials

Data and materials are available upon request.

Ethics approval and consent to participate

Not applicable

\section{Consent for publication}

Not applicable

\section{Competing interests}

The authors declare that they have no competing interests.

Received: 25 June 2020 Accepted: 31 August 2020

Published online: 13 October 2020

\section{References}

1. National Center for Biotechnology Information. Efonidipine hydrochloride, CID-119170. In: PubChem Database. https://pubchem.ncbi.nlm.nih.gov/ compound/Efonidipine-hydrochloride. Accessed 10 Apr 2020

2. Miyamoto M, Oda T, Bunrin T, Okabe T, Nishiyama T (2001) Process for producing efonidipine hydrochloride preparations. US Patent 6,171,599 (9 Jan 2001)

3. Otsuka M, Maeno Y, Fukami T, Inoue M, Tagami T, Ozeki T (2016) Solid dispersions of efonidipine hydrochloride ethanolate with improved physicochemical and pharmacokinetic properties prepared with microwave treatment. Eur J Pharm Biopharm 108(10):25-31

4. Huang S, Zhang Q, Li H, Sun Y, Cheng G, Zou M, Piao H (2018) Increased bioavailability of efonidipine hydrochloride nanosuspensions by the wetmilling method. Eur J Pharm Biopharm 130(9):108-114

5. Schilling SU, Shah NH, Malick AW, Infeld MH, McGinity JW (2007) Citric acid as a solid-state plasticizer for Eudragit RS PO. J Pharm Pharmacol 59(11): 1493-1500

6. Bruce LD, Shah NH, Malick AW, Infeld MH, McGinity JW (2005) Properties of hot-melt extruded tablet formulations for the colonic delivery of 5aminosalicylic acid. Eur J Pharm Biopharm 59(1):85-97

7. Bruce LD, Petereit HU, Beckert T, Mcginity JW (2003) Properties of enteric coated sodium valproate pellets. Int J Pharm 264(1-2):85-96

8. Ploen J, Andersch J, Heschel M, Leopold CS (2009) Citric acid as a pHmodifying additive in an extended release pellet formulation containing a weakly basic drug. Drug Dev Ind Pharm 35(10):1210-1218

9. Khan A, Iqbal Z, Khan A, Mughal MA, Khan A, Ullah Z, Khan I (2016) Modulation of $\mathrm{pH}$-independent release of a class II drug (domperidone) from a polymeric matrix using acidic excipients. Dissolution Technol 23(1): $32-40$

10. Liu M, Zhao H, Tong Y, Zhang D, Wang X, Zhang L, Liu H (2015) Determination of efonidipine in human plasma by LC-MS/MS for pharmacokinetic applications. J Pharm Biomed Anal 103(1):1-6

11. Liu M, Deng M, Zhang D, Wang X, Ma J, Zhao H, Zhang L, Tong Y, Liu H (2016) A chiral LC-MS/MS method for the stereospecific determination of efonidipine in human plasma. J Pharm Biomed Anal 122(4):35-41 
12. Kumar A, Shoni SK, Dahiya M, Kumar R, Yadav AK (2017) Development and validation of liquid chromatography (RP-HPLC) methodology for estimation of efonidipine $\mathrm{HCl}$ ethanolate (EFD). Pharm Anal Acta 8(5):1-6

13. Pandya CP, Rajput SJ (2020) Forced degradation study of efonidipine $\mathrm{HCl}$ ethanolate, characterization of degradation products by LC-Q-TOF-MS and NMR. J Appl Pharm Sci 10(4):75-99

14. ICH (2005). ICH Topic Q2 (R1) Validation of analytical procedures : text and methodology. Int Conf Harmon. https://www.gmp-compliance.org/ guidemgr/files/Q2(R1).pdf.

15. Gedawy A, Al-salami H, Dass CR (2019) Development and validation of a new analytical HPLC method for simultaneous determination of the antidiabetic drugs, metformin and gliclazide. J Food Drug Anal 27(1):315322

16. Vikas A, Rashmin P, Mrunali P, Sandip M, Kaushik T (2020) RP-HPLC method for quantitative estimation of Efinaconazole in topical microemulsion and microemulsion-based-gel formulations and in presence of its degradation products. Microchem J 155:104753

17. Attimarad M, Venugopala KN, SreeHarsha N, Aldhubiab BE, Nair AB (2020) Validation of rapid RP-HPLC method for concurrent quantification of amlodipine and celecoxib in pure and formulation using an experimental design. Microchem J 152:104365

18. Jha DK, Shah DS, Talele SR, Amin PD (2020) Correlation of two validated methods for the quantification of naringenin in its solid dispersion: HPLC and UV spectrophotometric methods. SN Appl Sci 2(4):1-11

19. Wiczling $P$, Kaliszan $\mathrm{R}$ (2008) Influence of $\mathrm{pH}$ on retention in linear organic modifier gradient RP HPLC. Anal Chem 80(20):7855-7861

20. Vella J, Mifsud M, Sammut Bartolo N, Ferrito V, Serracino-Inglott A, Azzopardi LM, Laferla G (2014) The combined effects of pH and acetonitrile composition on the separation of two Lincosamide antibiotics. Asian J Pharm Clin Res 7(5):96-100

21. Jha DK, Shah DS, Amin PD (2020) Thermodynamic aspects of the preparation of amorphous solid dispersions of Naringenin with enhanced dissolution rate. Int J Pharm 583(6):119363

\section{Publisher's Note}

Springer Nature remains neutral with regard to jurisdictional claims in published maps and institutional affiliations.

\section{Submit your manuscript to a SpringerOpen ${ }^{\circ}$ journal and benefit from:}

- Convenient online submission

- Rigorous peer review

- Open access: articles freely available online

High visibility within the field

- Retaining the copyright to your article

Submit your next manuscript at $\boldsymbol{\nabla}$ springeropen.com 